\title{
Vaccine against COVID-19: The holy grail and the elephant together in a room
}

\author{
Sanjeev Singh ${ }^{1}$, Sruti Singha Roy ${ }^{2}$, and Abhisek Dutta ${ }^{3}$ \\ ${ }^{1}$ Guru Gobind Singh Indraprastha University \\ ${ }^{2}$ University of Kalyani \\ ${ }^{3}$ Freelancer
}

June 2, 2020

\begin{abstract}
Throughout the history, pandemics have played a significant role in reshaping human civilizations. In this series, Severe Acute Respiratory Syndrome Coronavirus-2 (SARS-CoV-2), a new coronavirus strain causing novel Coronavirus-19 (COVID19) disease that has brought the entire world to its knees. The uncertainty revolving around the virus can spark beyond our imagination if not handled appropriately. Immunity against COVID-19 can be achieved in two ways - through natural infection or through vaccination against COVID-19. The second way is the most preferred one, is to develop a safe and effective vaccine and practice mass vaccination without enduring the significant loss of precious lives. However, efficiently developing and delivering a perfect vaccine on time under tremendous pressure to meet millions of expectations is not an easy task as there are many elephants in the room. Besides, we do need a strong, vigilant, and people-friendly healthcare delivery system to translate the vaccine into vaccination without any discrimination. Until such time the vaccine is developed and mass administration takes place the silver bullets against COVID-19 would be symptomatic treatment, avoid mass gathering, social distancing, frequent hand washing, wearing masks and gloves, and generating COVID-19 related awareness in the society.
\end{abstract}

\section{Hosted file}

COVID19 and Vaccines -R.doc available at https://authorea.com/users/315752/articles/456042vaccine-against-covid-19-the-holy-grail-and-the-elephant-together-in-a-room 